\title{
Evaluation of Osseointegration Ability of Porous Polyethylene Implant (Medpor) Treated with Chitosan
}

\author{
Kwang Kim, ${ }^{1}$ Byung-Hoon Kim, ${ }^{2}$ Seunggon Jung, ${ }^{3}$ Hong-Ju Park, ${ }^{3}$ \\ Seung-Ho Ohk, ${ }^{4}$ Hee-Kyun Oh, ${ }^{3}$ and Min-Suk Kook ${ }^{3}$ \\ ${ }^{1}$ School of Dentistry, Chonnam National University, Gwangju 500-757, Republic of Korea \\ ${ }^{2}$ Department of Dental Materials, School of Dentistry, MRC Center, Chosun University, \\ Gwangju 501-759, Republic of Korea \\ ${ }^{3}$ Department of Oral and Maxillofacial Surgery, School of Dentistry, Chonnam National University, Gwangju 500-757, Republic of \\ Korea \\ ${ }^{4}$ Department of Oral Microbiology, School of Dentistry, Chonnam National University, Gwangju 500-757, Republic of Korea
}

Correspondence should be addressed to Min-Suk Kook; omskook@jnu.ac.kr

Received 16 June 2014; Accepted 2 July 2014; Published 20 July 2014

Academic Editor: Seunghan Oh

Copyright (C) 2014 Kwang Kim et al. This is an open access article distributed under the Creative Commons Attribution License, which permits unrestricted use, distribution, and reproduction in any medium, provided the original work is properly cited.

Purpose. We suggest a successful and simple Medpor treated way with chitosan and evaluate more improved osseointegration ability of it than the orignal. Materials and Methods. Medpor was punched into circular shape and dipped into the chitosan gel solution. The Medpor plates soaked with chitosan were identified by the SEM images. We evaluated the growth rate of MC3T3-E1 cell using Von Kossa staining and MTT assay as in vitro experiment. And we implanted both Medpor plates into skull of domestic rabbits for in vivo experiment. We evaluated the osseointegration result with an optical microscope in postoperative 3 weeks and 6 weeks histologically. Results. The in vitro MC3T3-E1 cell growth rate on Medpor soaking with chitosan was faster than the original one in both Von Kossa staining and MTT assay. In animal test, Medpor soaking with chitosan shows more pronounced new bone than original Medpor too. Conclusion. Medpor soaking with chitosan was a successful modification. It is believed that the upgraded osseointegration ability of Medpor soaking with chitosan gives many benefits to clinicians using a Medpor implant for oral and maxillofacial reconstruction surgery.

\section{Introduction}

Many bone graft materials and bone substitution materials have been developed and used in reconstruction surgeries of a collapsed oral and maxillofacial anatomical structure as discussed by Neovius and Engstrand [1]. Autogenous, allogeneic, xenogeneic, and alloplastic materials are typical. Allogeneic bone, xenogeneic bone, and alloplastic material were getting better for recent several decades, but it might be so difficult that they catch up the regeneration and osseointegration ability of autogenous bone yet. But despite of the powerful ability, the autogenous bone has a certain clinical problem that the volume of donor site and the number of donating times are certainly limited and a lot of physiological strains on the host body are put by an additional operation. Many researches are doing research to find a new kind of graft material without thesesort of problems. Many of them are trying to develop a more powerful "modification" for xenogeneic and alloplastic materials than previous one or find new mimic material. In this study we chose porous high density polyethylene implant (Medpor) as a good alloplastic material of bone substitutive candidate.

A graft material acts a role of scaffold on a recipient site in tissue regeneration engineering field. A scaffold is not only a dimensional framework on which desired tissues locate and a passage and depository of communication signals and nutrients but also a driving factor which induce a tissue cell differentiated appropriately with signals, nutrients. A good 


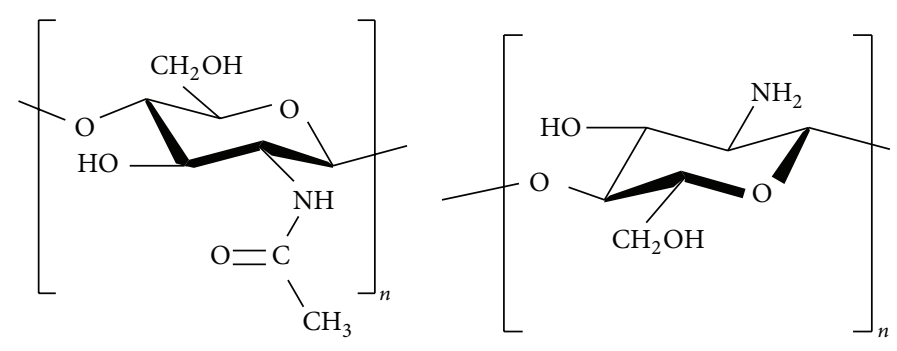

(a)

(b)

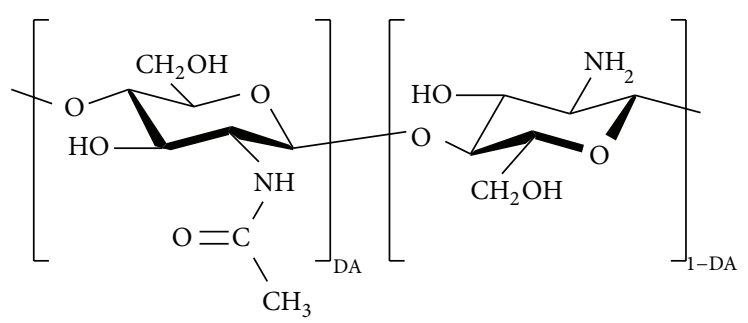

(c)

FIGURE 1: Chemical structure (a) of chitin poly(N-acetyl-b-D-glucosamine), (b) of chitosan (poly(D-glucosamine)) repeat units, and (c) structure of partially acetylated chitosan.

scaffold material has to satisfy following requirements: (1) biocompatibility with the host cells, (2) biodegradability at the ideal rate synchronizing with new differentiating tissue cells, (3) nontoxicity and nonimmunogenicity, (4) proper mechanical property, and (5) suitable porosity size and morphology for transporting of moving cells, gases, metabolites, nutrients, and signal molecules as discussed by Kim et al. [2].

Medpor is famous as one of good alloplastic materials for a bone reconstruction surgery as discussed by Berghaus [3]. It is known that Medpor has high biocompatibility with human host tissues, as many clinical application cases have been reported in medical literature. And as many critical postoperative complications caused by Medpor have not been reported to medical literature. That means Medpor has no toxicity. Because Medpor is enough inert and tolerative against a host defense system, especially enzyme and immune system of host, so Medpor would not be degraded easily in a physiologic environment. The multiporous structure of Medpor provides a settling space to new bone tissue cells as a good regenerating environment tube integrated with host bone tissue. The porous structure allows prominent vascularization and connective tissue ingrowth among the space too. And Medpor has ambivalent physical properties, not only flexibility to absorb the external shock and being easy to shape with routine surgical blade or scissors but also being enough rigid to maintain the contour firmly as discussed by Couldwell et al. [4]. So Medpor has been used for many clinical surgeries to reconstruct a collapsed anatomical structure caused by trauma or surgical resection. Medpor is a good alloplast for the chin, malar area, nasal reconstruction, ear reconstruction, orbital reconstruction, and the correction of mandibular contour deformities and so forth, all craniomaxillary reconstruction as discussed by elsewhere $[5,6]$. But despite the fact that Medpor satisfies many requirements as a substitute for collapsed bone, unfortunately it has no osteoinduction ability to regenerate new bone, because Medpor has no biodegradability and no activity to osteoinduce. Medpor does just role as substitution to fill defected bone space of host. The adhesive strength with the host bone is weak to fix firmly with host it is necessary to fix with a screw system that require an operating surgeon more endeavour. To improve osseointegration ability of Medpor with host bone, in this study we devised an advanced Medpor which is soaking with chitosan.

Chitosan is well known as a good scaffold material which induce a bone tissue regeneration as discussed by Madihally and Matthew [7]. Chitosan is the second most abundant linear polysaccharide in nature which is composed of glucosamine and $\mathrm{N}$-acetyl glucosamine linked in a $\beta$ (14) manner (Figure 1(b)) as discussed by Rinaudo [8]. The easiest way to obtain a chitosan is from nature chitin. Chitin (Figure 1(a)) is easily obtained from exoskeleton of crab or shrimp shells, lobsters, krill, insects, crustacea, and so forth. So the commercial price of chitosan is very cheap as discussed by Ravi Kumar [9]. Chitosan is obtained by deacetylation of chitin in the high $\mathrm{pH}$ condition. The hydrolysis of the acetyl moiety of chitin polymer using a mixture of anhydrous hydrazine and aqueous sodium hydroxide or potassium hydroxide solution changed chitin into chitosan (Figure 1(c)) as discussed by Dash et al. [10]. Of course Chitosan is a nontoxic, biologically compatible polymer approved by the FDA for use in wound healing as discussed by Thanou et al. [11]. But some moiety change on chitosan could make it more or less toxic. In this study, we note the osteoinduction ability of chitosan to promote cell growth and to provide mineral rich matrix deposition as discussed by Kean and Thanou [12]. Enzymatically, chitosan can be degraded by enzymes like human chitinases which can hydrolyze between glucosamine linkages and depolymerize through oxidationreduction reaction. And free radical degradation of chitosan 


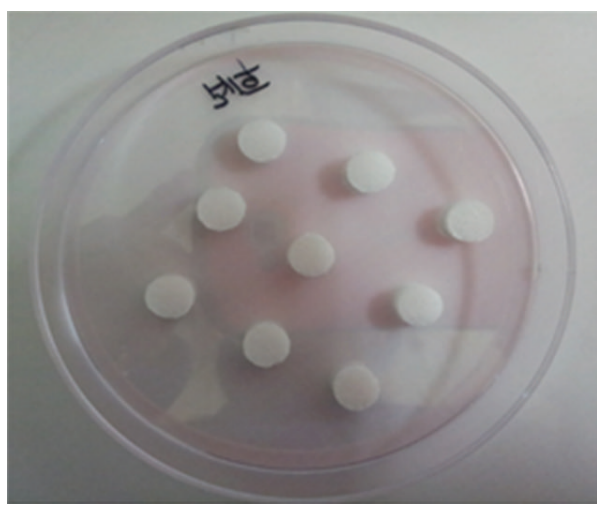

(a)

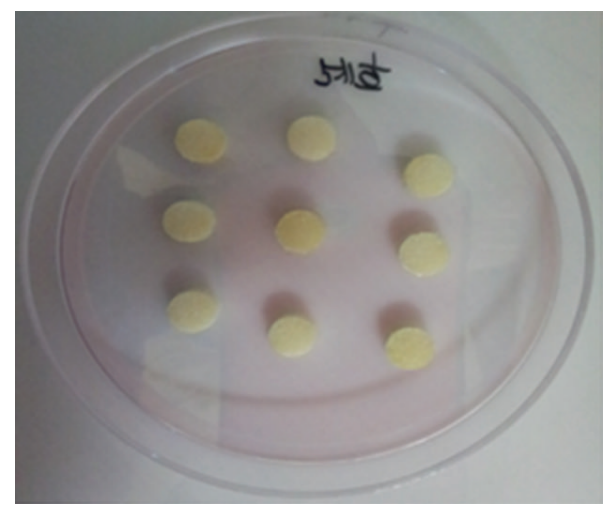

(b)

FIGURE 2: Gross findings of the porous polyethylene (Medpor) plates shaped by puncture into circular form. (a) Original nonsoaking Medpor plates. (b) Medpor soaking with chitosan plates. The color of Medpor plates changed into yellowish after coating process.

plays a main role in the in vivo degradation. The degraded mineral rich matrixes not only induce host cell growth hormone but also provide mineral resource to regenerating osteoblasts. So chitosan has been used for a scaffold material to reconstruct a collapsed anatomical structure of patients too.

As the Medpor porous structure provides a strong spacious framework and chitosan could induce the bone generation effect, the Medpor soaking with chitosan will be good bone substitution alloplastic material. In particular the boundary site of Medpor soaking with chitosan will be integrated with host bone tissue firmly, and maybe no more screw fixation will be required to fix it with host bone. In this study we designed simple chitosan treated process on Medpor and evaluated its osseointegration ability histologically through in vitro and in vivo test compared with original one.

\section{Materials and Methods}

2.1. Medpor Plate Soaking with Chitosan and Surface Characterization. Manufactured porous polyethylene implant plate (Medpor Surgical Implant $38 \times 50 \times 1.0 \mathrm{~mm}^{3}$ ) was punched into circular shape plate with each $8 \mathrm{~mm}$ (for in vivo rabbit implant experiment) diameters puncher (BIOPSY PUNCH $8 \mathrm{~mm} / \mathrm{USA}$ ). Chitosan (sigma, USA) $2.0 \mathrm{~g}$ and $99.5 \%$ acetic acid $1 \mathrm{~mL}$ mixed into distilled water $30 \mathrm{~mL}$. The half of prepared circular Medpor plates was dipped into the chitosan gel solution in $42^{\circ} \mathrm{C}$ water bath. It took about 3 days until all chitosan dissolved into the solution completely. After 3 days, we picked up all Medpor plates and dried them clearly. The weight of the original Medpor plates (A) was $0.93 \mathrm{~g}$. After the coating process, the mean weight of the Medpor plates (B) changed into $2.29 \mathrm{~g}$. We could guess that $1.36 \mathrm{~g}$ of chitosan was soaking on the Medpor plates $(\mathrm{B}-\mathrm{A}=1.36 \mathrm{~g})$. The visible change by coating process was about the color of Medpor plates. The white color of the Medpor plates changed into yellowish one (Figure 2(b)). To investigate whether chitosan could be well soaking on the Medpor plates, we took its
SEM image. The surface morphology of pristine Medpor plates and chitosan soaked Medpor plates were observed by scanning electron microscopy (JSM-7500F+EDS, Japan). The substrates were coated with gold using a sputter-coater (OPC80T, Japan). The SEM was operated at $15 \mathrm{kV}$ of acceleration voltage.

\subsection{In Vitro Cell Differentiation on Medpor Soaking with Chitosan}

2.2.1. MC3T3-E1 Cell Culture. Alpha-Minimum Essential Medium ( $\alpha$-MEM, gibco/USA) $500 \mathrm{~mL}, 10 \%$ Fetal Bovine Serum (FBS, gibco/USA) $50 \mathrm{~mL}$, and $1 \%$ penicillin $5 \mathrm{~mL}$ were mixed in 500:50:5 ratio. The MC3T3-E1 cell frozen in the liquid nitrogen tank was quickly thawed in a $37^{\circ} \mathrm{C}$ water bath. In the clean bench we gently mixed the cell and the MEM $9 \mathrm{~mL}$ into $15 \mathrm{~mL}$ conical tube using a micropipette. Cell pellets were acquired using a centrifugation $(1200 \mathrm{rpm}, 3 \mathrm{~min})$ and a floating MEM was removed from conical tube except the cell pellets. Cell pellets were dissolved carefully into a new MEM $5 \mathrm{~mL}$ in the conical tube with a micropipette. The MC3T3-E1 cells were seeded at a MEM $5 \mathrm{~mL}$ in a $100 \phi$ dish and diffused homogeneously by slow rotating motion. We confirmed the cells diffusing condition with a microscope. After the preparation, the cells were incubated for 2 days at $37^{\circ} \mathrm{C}$ in a $\mathrm{CO}_{2}$ shaking incubator. Cell cultures were performed in passage 4 .

We removed the medium completely from the culture $100 \phi$ dish and washed it with PBS $2 \mathrm{~mL}$ and remove PBS completely too. After washing it, we added a trypsin-EDTA (USA/gibco) $2 \mathrm{~mL}$ to the cell dish. The cells were incubated for 3 minutes at $37^{\circ} \mathrm{C}$ again in a $\mathrm{CO}_{2}$ incubator. The detached cell condition was checked through a microscope. To deactivate trypsin-EDTA we added MEM $3 \mathrm{~mL}$ into the cell dish. Cell pellets were acquired again using a centrifugation (1200 rpm, $3 \mathrm{~min}$ ) and a floating medium was removed from the conical tube. A new MEM $500 \mu \mathrm{L}$ was added into the tube to dissolve the cell pellets. To count cells we used trypan blue assay. The cell suspension $20 \mu \mathrm{L}$ and trypan blue $20 \mu \mathrm{L}$ were mixed in the same volume and washed with $70 \%$ ethyl alcohol 
and cell counted using a microscope. The numbers of the cell were $142.5 \times 10^{4}$.

\subsubsection{MTT Assay for MC3T3-E1 Cell Proliferation. To} observe the cell proliferation we seeded each of $1 \times 10^{4}$ MC3T3-E1 cells into the normal Medpor plates, Medpor plates soaking with chitosan, and control sample on the 24well plate. After the seeding finished, the 24 -well plate was incubated for 4 hours in a $\mathrm{CO}_{2}$ incubator at $37^{\circ} \mathrm{C}$. After incubation, DMSO $150 \mu \mathrm{L}$ was injected into each Medpor well and the plate was agitated for $30 \mathrm{~min}$. After removal of MTT solution, absorbencies of all samples were measured at $570 \mathrm{~nm}$ using a microplate reader. The MTT assay is described elsewhere [13].

\subsubsection{Von Kossa Staining. Consider}

(i) $5 \%$ silver nitrate solution (silver nitrate $(99.0 \%$, sigma/USA) $5.0 \mathrm{~g}+$ D-D.W $100 \mathrm{~mL}$ )

(ii) $5 \%$ sodium thiosulfate (sodium thiosulfate $(99.0 \%$, sigma/USA) $5.0 \mathrm{~g}+$ D-D.W $100 \mathrm{~mL}$ )

(iii) nuclear Fast Red solution (Aluminum sulfate (99.0\%, sigma/USA) $25.0 \mathrm{~g}+$ D-D.W $500 \mathrm{~mL}+$ nuclear fast $\operatorname{rad} 0.5 \mathrm{~g})$.

We seeded each of $1 \times 10^{4}$ MC3T3-E1 cells into the original Medpor plates, Medpor plates soaking with chitosan, and control sample on the 96-well plate. We seeded control group on the next site together. After the seeding finished, the 96-well plate was incubated for 10 days doing exchange the medium every 2 days. And after the incubation each well was washed three times with PBS. To fix the cell we dipped the well plate into $70 \%$ ethanol solution for 10 minutes and washed it with D-D.W. Using nuclear fast red solution every sample was stained for 5 minutes and washed three times with D-D.W and observed the color changes of the samples.

2.2.4. Statistical Methods. We used a SPSS 21.0 program (IBM Co., Armonk, USA) for statistical analysis. Normality Test of the measurement values of each group was performed. Data are presented as mean \pm standard deviation for growth cell rate results of the MC3T3-E1 cells relative to the control sample as $100 \%$. Statistical significance was determined by independence $t$-test. The differences were considered to be statistically significant at $P<0.05(n=9)$.

\subsection{Animal Experimental Study of Osseointegration Ability}

2.3.1. Medpor Sample Implant Surgery on the Skull of a Domestic Rabbit. This study was performed in accordance with the Institutional Guidelines for Experimental Animal Care and Use of Chonnam National University (CNU IACUC-H-20146).

Six domestic rabbits under general anesthesia were prepared using Xylazine (Rompun, Bayer Korea, Korea) $10 \mathrm{mg} / \mathrm{kg}$ and Zoletil (Zoletil50, Virbac Co, France) $50 \mathrm{mg} / \mathrm{kg}$. After fur removal to expose the skull sterilized with Povidone-iodine (Potadine, Korea), we injected 2\% lidocaine with 1:100,000 epinephrine locally around the surgical site

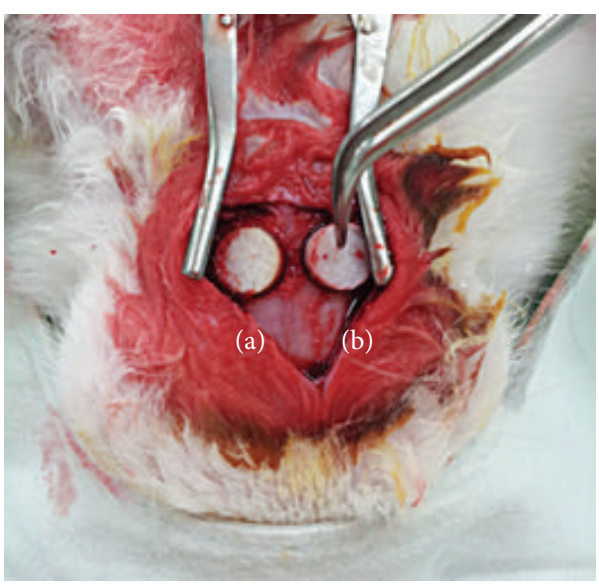

FIGURE 3: In vivo Medpor implant surgery on the skull of a rabbit. (a) original Medpor plate on right side (control) and (b) Medpor plate soaking with chitosan on left side (experimental).

of rabbits. Using a surgical blade the skulls of rabbits were exposed enough and the skull of each of the rabbits was punched twice with $8 \mathrm{~mm}$ trephine bur. And a Medpor plate soaking with chitosan was located on the right punched side of each rabbit and the other normal Medpor was located on the other left side and sutured the surgical site firmly (Figure 3). The surgical site was washed with saline and sterilized with potadine. Amoxicillin and anti-inflammatory drug were treated in intramuscular injection.

2.3.2. Histological Evaluation of Samples. At 3 weeks and 6 weeks after surgery, all rabbits were sacrificed by an excess injection of pentothal sodium and exposed the surgical site. All Medpor implants including the surrounding bone were resected and trimmedinto a proper shape. And we fixed the fresh bone with Schaffer's solution $(2 / 3$ of $96 \%$ ethanol + $1 / 3$ of $37 \%$ formaldehyde). After serial dehydration without any decalcification, the bone samples were embedded into methylmethacrylate solution. All Medpor implants were cut into $300 \mu \mathrm{m}$ thickness by a diamond saw along the major axis of the thickest area of each implant. And those samples were ground with a grinder-polisher (Metaserv, Buehler, USA) into $50 \mu \mathrm{m}$ thickness. Those samples were stained using $\mathrm{H} \& \mathrm{E}$ and observed through the microscope (Nikon Inc., Melville, NY, USA) histologically. Using Aperio Image Scope v9.1 (ImageScope, Aperio Technologies Inc., Vist, CA, USA) we obtained the histological digital images of the stained slice samples. We focused osseointegration level and treatment level around the periphery of each implant.

\section{Results}

3.1. Medpor Plate Coating with Chitosan. To investigate whether chitosan could be well soaking on the Medpor plates, we took a SEM image (Figure 4). As compared to the $\times 50$ images, the Medpor plate samples treated with chitosan has shown that fines with a smooth surface covered the surface between polyethylene frameworks. The space of scaffolds of 


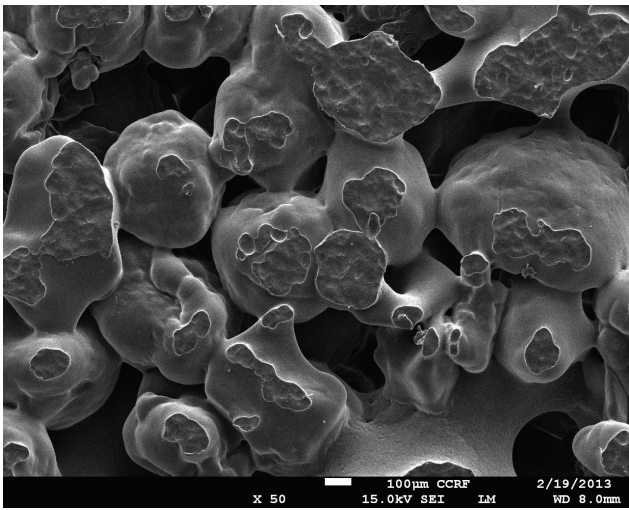

(a)

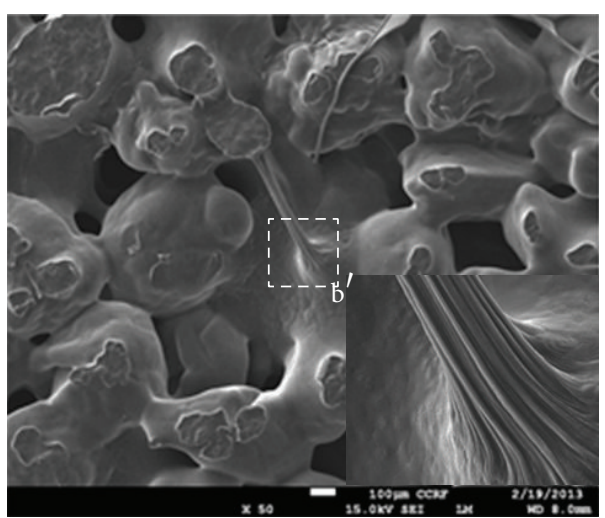

(b)

FiguRE 4: Scanning electron micrographs of the Medpor implant: (a) and (b) $\times 50$ images; $\left(b^{\prime}\right)$ image in the (b) image is $\times 500$ image of $(b)$. (a) Image includes the section of original Medpor and (b); $\left(\mathrm{b}^{\prime}\right)$ images include the section of Medpor plates treated with chitosan. The (b) image shows a smooth surface made of chitosan and the $\left(\mathrm{b}^{\prime}\right)$ image shows the root part of a columnar structure made of chitosan.

Medpor plates became narrower than the original Medpor plate samples. Some columnar chitosan crystal was observed in a porous framework (Figure 4(b)).

3.2. In Vitro Cell Differentiation on Medpor Soaking with Chitosan. To investigate MC3T3-E1 cell differentiation capacity on Medpor we performed several analyses including Von Kossa staining and MTT assay. The Von Kossa staining result was observed by naked eye. The left side line of the Figure 5 is the wells of the original Medpor samples and the right side line is chitosan coating Medpor. The red color dye stained the well-differentiated MC3T3-E1 cells for the new bone generation. As you see, the right side of the wells shows more reddish color than the left side. It means that Medpor soaking with chitosan has better osteoinduction ability than the original one in the differentiation of bone regeneration cell.

In MTT assay the growth rate of the MC3T3-E1 was converted with absorbance in $570 \mathrm{~nm}$ relative to the absorbance of control group. The result is the diagram of Figure 6. As you see it, the Medpor soaking chitosan showed about 23\% (deviation of mean is $2.52 \%$ ) higher growth rate than the control and original Medpor showed about 13\% higher than the control. And the mean growth rate of the MC3T3-E1 is statistically significantly different between two groups $(P=$ 0.008 , Figure 6).

3.3. Evaluation of Osseointegration Ability in Animal Study. The regeneration state of each rabbit's sample was evaluated in histological method. H\&E dye is adequate dye to stain an alive bone tissue specifically. But Medpor is not stain with H\&E dye, so we can identify ivory color Medpor. The pink color between porous structures of Medpor, which can provide strong osseointegration with host bone tissue, is stained new bone matrix.

In Figure 7 corresponding to 3 weeks of postsurgery the stained new bone matrix of right column, Medpor soaking with chitosan, is more pinkish than the one of left column.

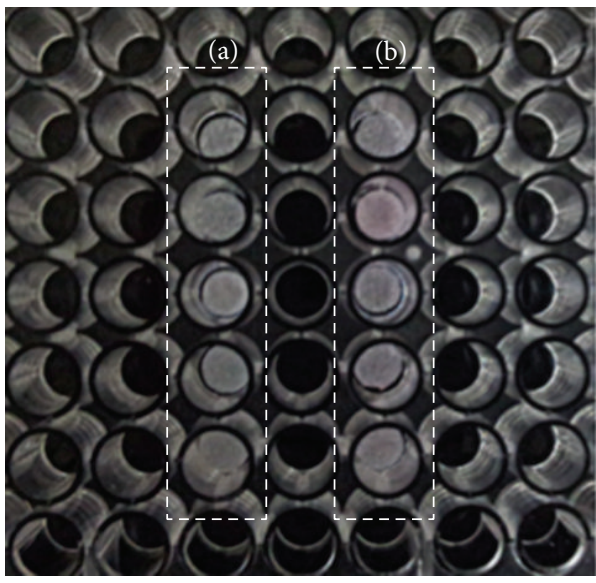

FIgURE 5: Gross finding of Von Kossa staining result. (a) Original Medpor and (b) Medpor soaking with chitosan. (b) Samples showed the color change in red.

Particularly focusing the periphery of implant Medpor soaking with chitosan shows more pronounced color than original Medpor. In some area the dark red of (a) looks like redder than $\left(\mathrm{a}^{\prime}\right)$, but it is just coagulation product of blood and not new bone matrix. In Figure 8 corresponding to 6 weeks of postsurgery the stained new bone matrix of right column, Medpor soaking with chitosan, is more pinkish than the one of left column too. Around the periphery of implant, the color difference is more pronounced too. The clear boundary of the new bone tissue proves a strong osseointegration with host bone tissue.

\section{Discussion}

Recently, Medpor has been excellent alternative to autogenous bone grafts for facial skeletal augmentation clinically. Medpor is useful in treatment for a variety of facial skeletal 


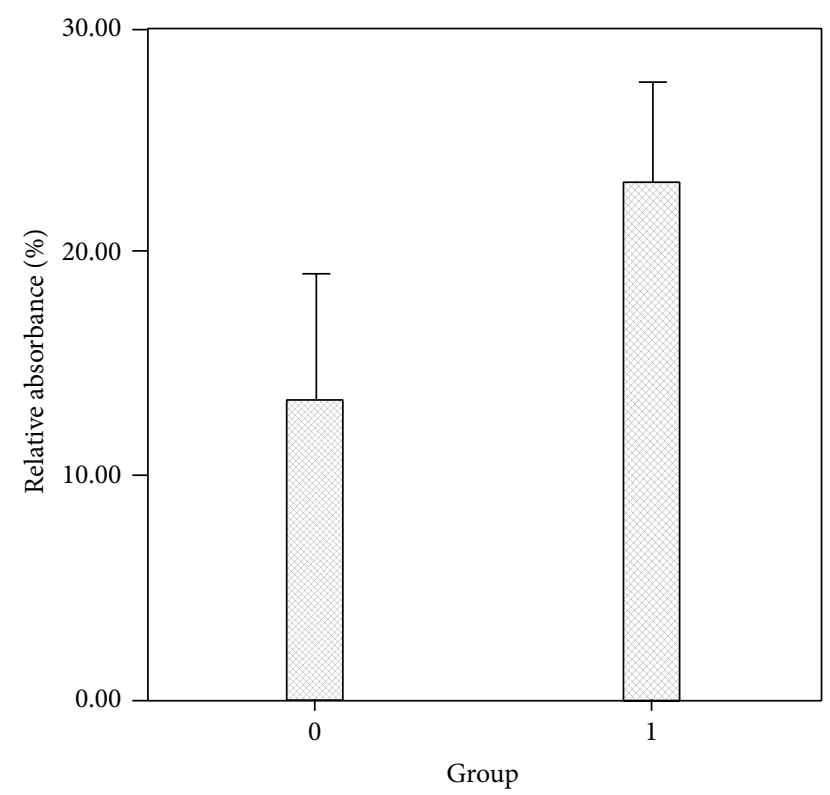

FIGURE 6: The converted absorbance bar diagram for growth cell rate results of the MC3T3-E1 cells relative to the control sample TCP as $100 \%$; the left bar (group 0) is for the original Medpor and the right bar (group 1) is for the Medpor soaking chitosan. Data are presented as mean \pm standard deviation with $n=9(P<0.05)$.

deformities despite of some disadvantages including its rigidity and palpability extraorally as discussed by Rai et al. [14]. They have fundamentally high biocompatibility, low toxicity, low immune reaction, and proper porous structure which provide a passage and a space to undifferentiated mesenchymal cell, gases, metabolites, nutrients, and several signal molecules and their characteristics were reported many times through biological and medical literature.

While Medpor has a relatively rigid and stable structure it has poor osseointegration ability with host bone. Medpor implants in vivo in animal experiments showed both soft tissue and bony ingrowth into its pores and these results give a belief that Medpor has osteoconduction activity, but unfortunately Medpor has no osteogenic effect through osteoconductive activity even in young children as discussed by Tark et al. [15]. So to implant Medpor, we have to fix it with a screw as discussed by Couldwell et al. [4].

To improve the osteoconductive activity of Medpor, variety of modifications were perfumed. Cowieson et al. tried plasma polymerization for molecularly imprinted polymer to porous polyethylene filtration membranes [16]. Since there was no significant change in the porosity of the modified membranes, it was assumed that only a thin layer of the polymer was introduced on the surface of the herbicide atrazine as a template. The plasma polymerization can give the free formation ability and rigid adhesive effect, but it seems too difficult to control the plasma quite freely.

Ehrmantraut et al. perfumed to make a Medpor plate with chondrocytes to promote early implant vascularization and incorporation into host tissues [17]. Adequate vascularization provides a successful incorporation of the alloplastic biomaterial. If vitalization with human chondrocytes can accelerate the early vascularization of porous polyethylene the osseointegration ability will be better. Polyethylen samples were coated with platelet-rich plasma (PRP) and it improved vascularization compared with controls. And they prevented the accumulation of macrophages and foreign body giant cells on the polyethylene surface. But PRP is too expensive to manufacture. The coating process is so difficult because it requires a careful biological process to protect the protein in PRP.

Kalwerisky et al. examined silicon-capped porous polyethylene spherical implants and evaluated the rate of vascularization that is important to osseointegration [18]. In this animal experiment, no fibrovascular ingrowth occurred at the interface between the silicone cap and the porous polyethylene implant and no significant host inflammatory response and no implant exposure which is main complication of using porous polyethylene spherical implants as discussed by Sevin et al. [19]. Silicon capped implant that resists exposure without the need for a wrapping material and achieves successful biointegration soon after implantation. But Silicon capping process is not so easy to manufacture.

If chitosan can be used like an adhesive scaffold for osseointegration with host bone, the fixation process in an implant surgery using Medpor will be not required anymore. So the surgery process using Medpor can be more biocompatible. Some modification method was shown using chitosan, for example, a hydrogel form by ethylene glycol chitosan introduced by Chen et al. [20]. Chemical or physical crosslinker which could combine the advantages of the two kinds of hydrogels gives the formation result of a covalent bone with a host tissue and it is a promising tissue engineering scaffold.

Because chitosan is so naturally more abundant and economically cheaper than other additive candidates to modify Medpor, the reasonable price of the production will be expected. The low cost of chitosan coating implant production may reduce the financial burden not only of implant commercial providers but also of recipient patients. The simple coating process will promise the easier commercialization than another substitution coating materials too.

For this study a relatively simple method for coating a chitosan to Medpor was suggested. Changing the solubility of the chitosan, by increasing the $\mathrm{pH}$ of the solvent and dipping Medpor into the concentrated chitosan solution for a long time through a process, chitosan can successfully be soaking onto Medpor. Successful coating result was confirmed by STM images analysis.

The bone regeneration ability and marginal osseointegration with host bone of Medpor soaking with chitosan were proven through in vitro M3TC3 cell differentiation experiments and in vivo bone formation experiments. Neither in vitro experiment of cell differentiation nor in vivo experiments of bone regeneration could evaluate a numerical result of osseointegration by physical test. To acquire confirmation about the osseointegration, a succeeding research may be needed. But through these experimental result, we cannot ignore that the osseointegration capability in the junction 


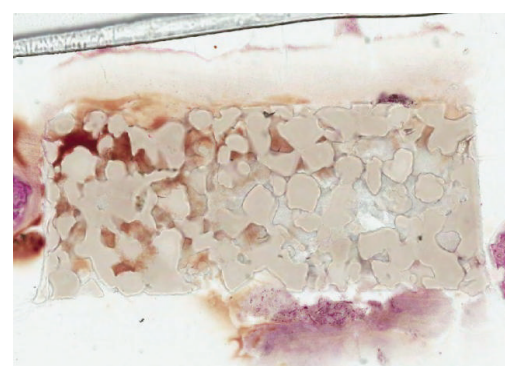

(a)

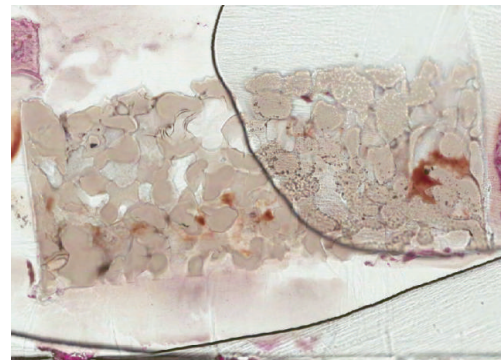

(b)

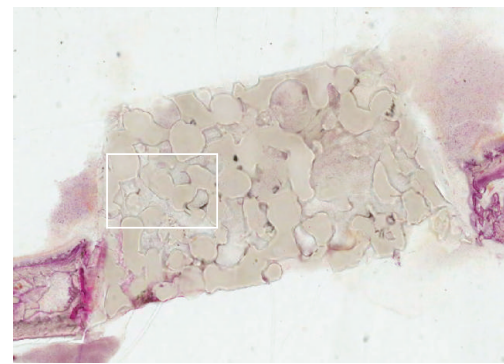

(c)

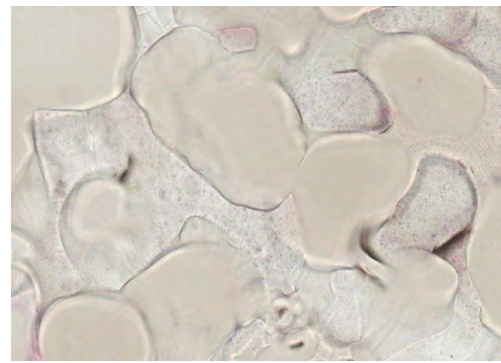

(d)

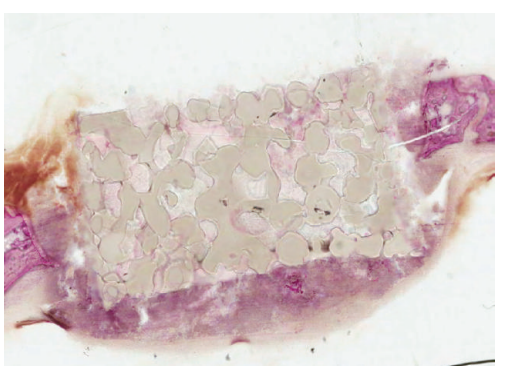

$\left(a^{\prime}\right)$

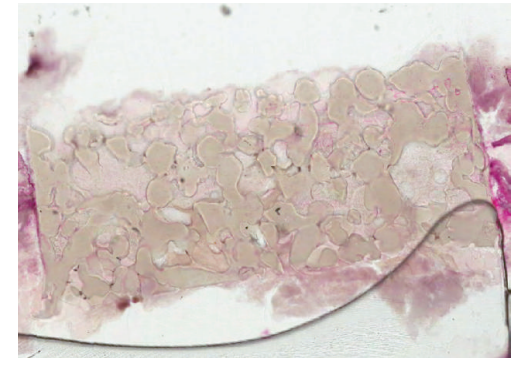

$\left(b^{\prime}\right)$

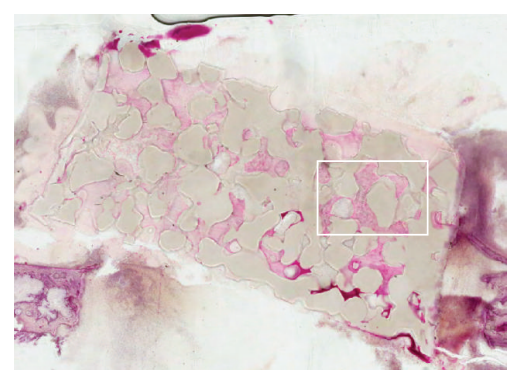

$\left(c^{\prime}\right)$

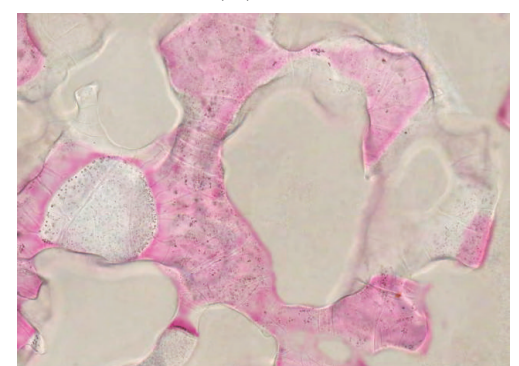

$\left(\mathrm{d}^{\prime}\right)$

FIGURE 7: The whole and local tomography of histologic images of the Medpor plates implanted into skulls of 3 rabbits at 3 weeks after surgery. All bone tissue sample was stained with H\&E dye. The images of original Medpor are on left column (a, b, c, and d) and the images of Medpor soaking with chitosan are on right column $\left(a^{\prime}, b^{\prime}, c^{\prime}\right.$, and $\left.d^{\prime}\right)$. Same alphabet means same rabbit $\left(e x . a=a^{\prime}\right)$. Image of $(d)$ is zooming in local part of $(\mathrm{c})$, and $\left(\mathrm{d}^{\prime}\right)$ is zooming in local part of $\left(\mathrm{c}^{\prime}\right)$. The pink color means alive new bone tissue which provides strong osseointegration ability with host bone tissue.

between host bone and newly formed bone Medpor was relatively considerable than in the case of original Medpor, although the coating method was simple and cheap.

For better osseointegration ability of Medpor soaking chitosan, it is necessary to devise a modified soaking process which can facilitate penetration of the core. We could suggest and try a new modification method to obtain the efficiently absorbed Medpor using a weak negative pressure of vacuum utility as discussed by James et al. [21]. We guess that the simple method would make a dramatic improvement of efficiency. Or a high concentration chitosan solution can be injected from the inside of Medpor or the artificial flow of chitosan solutioncan be considerable. The temperature condition and the adjustment of the concentration of the chitosan can be used. It seems that there is room to make several upgrade coating methods. Not just only methodological research but also the retrospective researches to identify the osseointegration of new Medpor are expected now. 


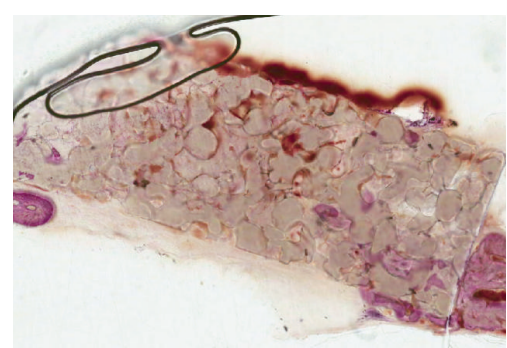

(a)

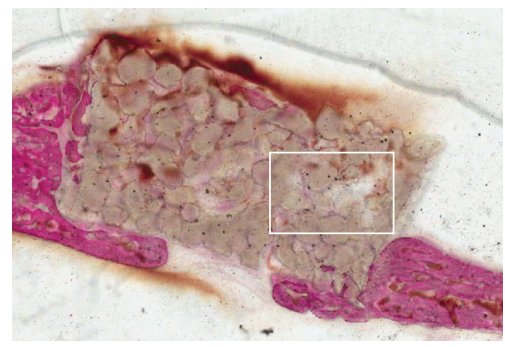

(b)

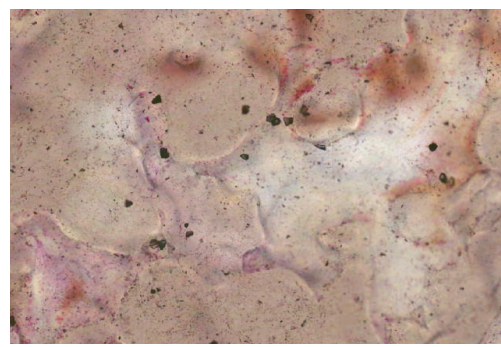

(c)

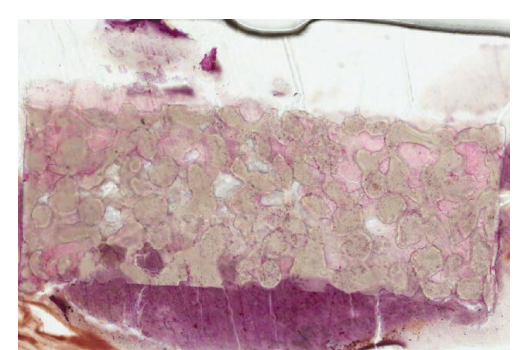

$\left(a^{\prime}\right)$

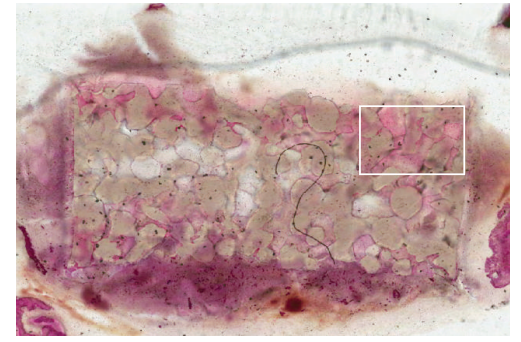

$\left(b^{\prime}\right)$

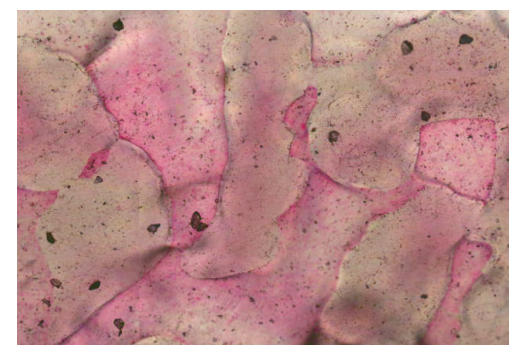

$\left(c^{\prime}\right)$

FIGURE 8: The whole and local tomography of histologic images of the Medpor plates implanted into skulls of 2 rabbits at 6 weeks after surgery. All bone tissue sample was stained with H\&E dye. The images of original Medpor are on left column (a, b, and c) and the images of Medpor soaking with chitosan are on right column $\left(a^{\prime}, b^{\prime}\right.$, and $\left.c^{\prime}\right)$. Same alphabet means same rabbit $\left(e x . a=a^{\prime}\right)$. Image of $(c)$ is zooming in local part of $(b)$, and $\left(c^{\prime}\right)$ is zooming in local part of $\left(b^{\prime}\right)$. The pink color means alive new bone tissue which provides strong osseointegration ability with host bone tissue.

\section{Conclusion}

Following this research of our group, we could conclude that Medpor soaking with chitosan was a successful modification in not only in vitro test but also in vivo test. It is especially confirmed by the animal histological evaluation that the osseointegration around the boundary between the Medpor soaking with chitosan implant and the host bone tissue is more pronounced than the original Medpor. It is believed that the upgraded osseointegration ability of Medpor soaking with chitosan gives many benefits to clinicians using a Medpor implant for oral and maxillofacial reconstruction surgery.

\section{Conflict of Interests}

The authors declare that there is no conflict of interests regarding the publication of the paper.

\section{Authors' Contribution}

Kwang Kim and Byung-Hoon Kim contributed equally to this work.

\section{Acknowledgments}

This research was financially supported by the Ministry of Knowledge Economy (MKE), Korea Institute for Advancement of Technology (KIAT), and Honam Leading Industry Office through the Leading Industry Development for Economic Region and by the National Research Foundation of Korea (NRF) Grant funded by the Korea government (MSIP) (2011-0030121).

\section{References}

[1] E. Neovius and T. Engstrand, "Craniofacial reconstruction with bone and biomaterials: review over the last 11 years," Journal of Plastic, Reconstructive \& Aesthetic Surgery, vol. 63, no. 10, pp. $1615-1623,2010$. 
[2] I. Kim, S. Seo, H. Moon et al., "Chitosan and its derivatives for tissue engineering applications," Biotechnology Advances, vol. 26, no. 1, pp. 1-21, 2008.

[3] A. Berghaus, "Porous polyethylene in reconstructive head and neck surgery," Archives of Otolaryngology, vol. 111, no. 3, pp. 154$160,1985$.

[4] W. T. Couldwell, T. C. Chen, M. H. Weiss, T. Fukushima, and W. Dougherty, "Cranioplasty with the medpor porous polyethylene Flexblock implant. Technical note," Journal of Neurosurgery, vol. 81, no. 3, pp. 483-486, 1994.

[5] T. Wellisz, "Clinical experience with the Medpor porous polyethylene implant," Aesthetic Plastic Surgery, vol. 17, no. 4, pp. 339-344, 1993.

[6] K. G. Patel and J. M. Sykes, "Use of Medpor implants in rhinoplasty surgery," Operative Techniques in Otolaryngology, vol. 19, no. 4, pp. 273-277, 2008.

[7] S. V. Madihally and H. W. T. Matthew, "Porous chitosan scaffolds for tissue engineering," Biomaterials, vol. 20, no. 12, pp. 1133-1142, 1999.

[8] M. Rinaudo, "Chitin and chitosan: properties and applications," Progress in Polymer Science, vol. 31, no. 7, pp. 603-632, 2006.

[9] M. N. V. Ravi Kumar, "A review of chitin and chitosan applications," Reactive \& Functional Polymers, vol. 46, no. 1, pp. 1-27, 2000.

[10] M. Dash, F. Chiellini, R. M. Ottenbrite, and E. Chiellini, "Chitosan-a versatile semi-synthetic polymer in biomedical applications," Progress in Polymer Science, vol. 36, no. 8, pp. 9811014, 2011.

[11] M. Thanou, J. C. Verhoef, and H. E. Junginger, "Oral drug absorption enhancement by chitosan and its derivatives," Advanced Drug Delivery Reviews, vol. 52, no. 2, pp. 117-126, 2001.

[12] T. Kean and M. Thanou, "Biodegradation, biodistribution and toxicity of chitosan," Advanced Drug Delivery Reviews, vol. 62, no. 1, pp. 3-11, 2010.

[13] S. Jung, K. Lee, and B. Kim, "Biocompatibility of plasma polymerized sandblasted large grit and acid titanium surface," Thin Solid Films, vol. 521, pp. 150-154, 2012.

[14] A. Rai, A. Datarkar, A. Arora, and D. G. Adwani, "Utility of high density porous polyethylene implants in maxillofacial surgery," Journal of Maxillofacial and Oral Surgery, vol. 13, no. 1, pp. 4246, 2014.

[15] W. H. Tark, I. S. Yoon, D. K. Rah, B. Y. Park, and Y. O. Kim, "Osteoconductivity of porous polyethylene in human skull," Journal of Craniofacial Surgery, vol. 23, no. 1, pp. 78-80, 2012.

[16] D. Cowieson, E. Piletska, E. Moczko, and S. Piletsky, "Grafting of molecularly imprinted polymer to porous polyethylene filtration membranes by plasma polymerization," Analytical and Bioanalytical Chemistry, vol. 405, no. 20, pp. 6489-6496, 2013.

[17] S. Ehrmantraut, A. Naumann, V. Willnecker et al., "Vitalization of porous polyethylene (Medporß) with chondrocytes promotes early implant vascularization and incorporation into the host tissue," Tissue Engineering A, vol. 18, no. 15-16, pp. 15621572, 2012.

[18] K. Kalwerisky, L. Mihora, C. N. Czyz, J. A. Foster, and D. E. E. Holck, "Rate of vascularization and exposure of silicone-capped porous polyethylene spherical implants: an animal model," Ophthalmic Plastic and Reconstructive Surgery, vol. 29, no. 5, pp. 350-356, 2013.

[19] K. Sevin, I. Așkar, A. Saray, and E. Yormuk, "Exposure of high-density porous polyethylene (Medpor) used for contour restoration and treatment," The British Journal of Oral and Maxillofacial Surgery, vol. 38, no. 1, pp. 44-49, 2000.
[20] Z. Chen, M. Zhao, K. Liu, Y. Wan, X. Li, and G. Feng, "Novel chitosan hydrogel formed by ethylene glycol chitosan, 1, 6-diisocyanatohexan and polyethylene glycol-400 for tissue engineering scaffold: in vitro and in vivo evaluation," Journal of Materials Science: Materials in Medicine, 2014.

[21] G. J. James, R. J. Moore, and M. J. Perry, "Impregnation of antibiotic into porous high density polyethylene material (Medpor) using negative pressure," The British Journal of Oral and Maxillofacial Surgery, vol. 44, no. 6, pp. 556-557, 2006. 

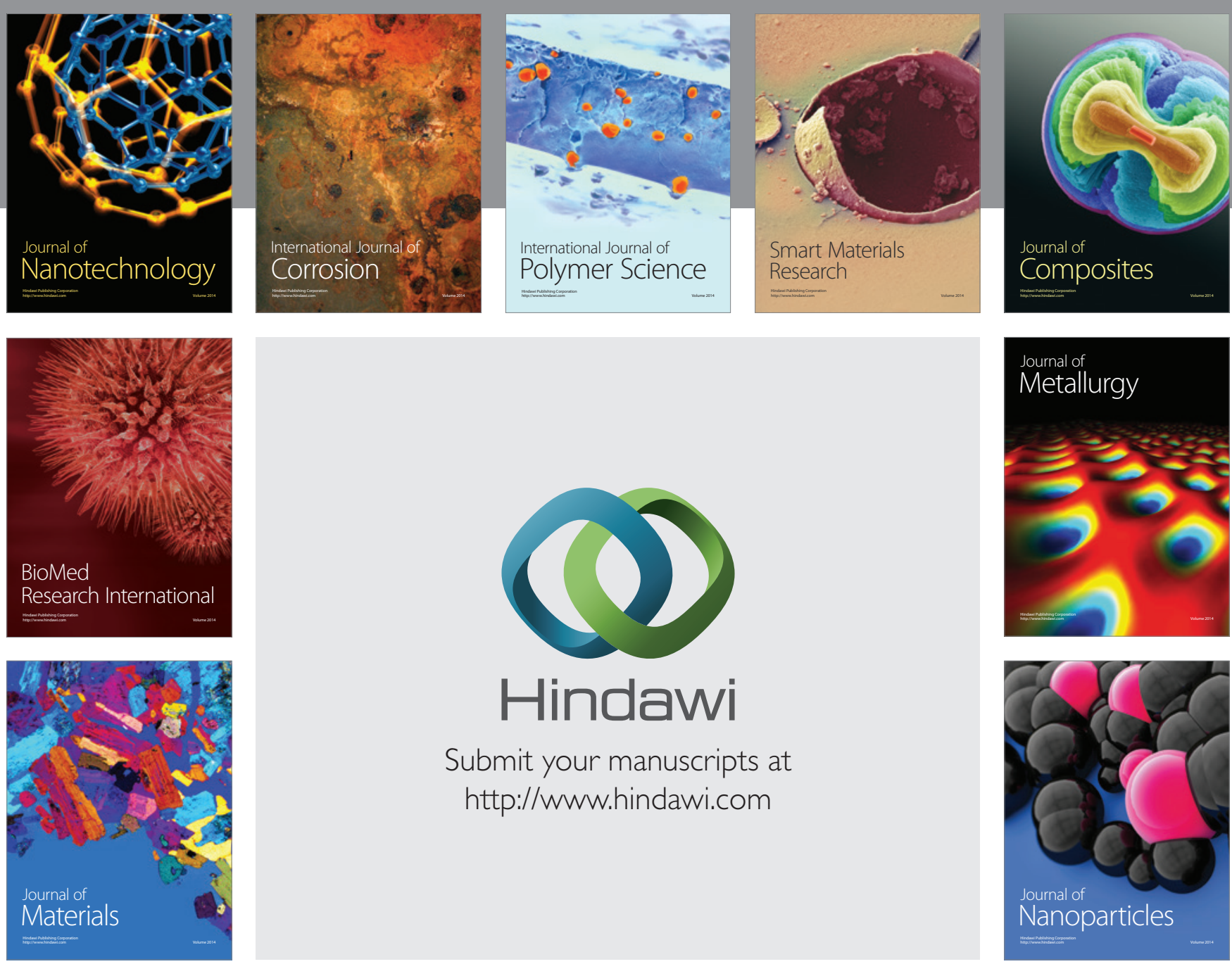

Submit your manuscripts at http://www.hindawi.com
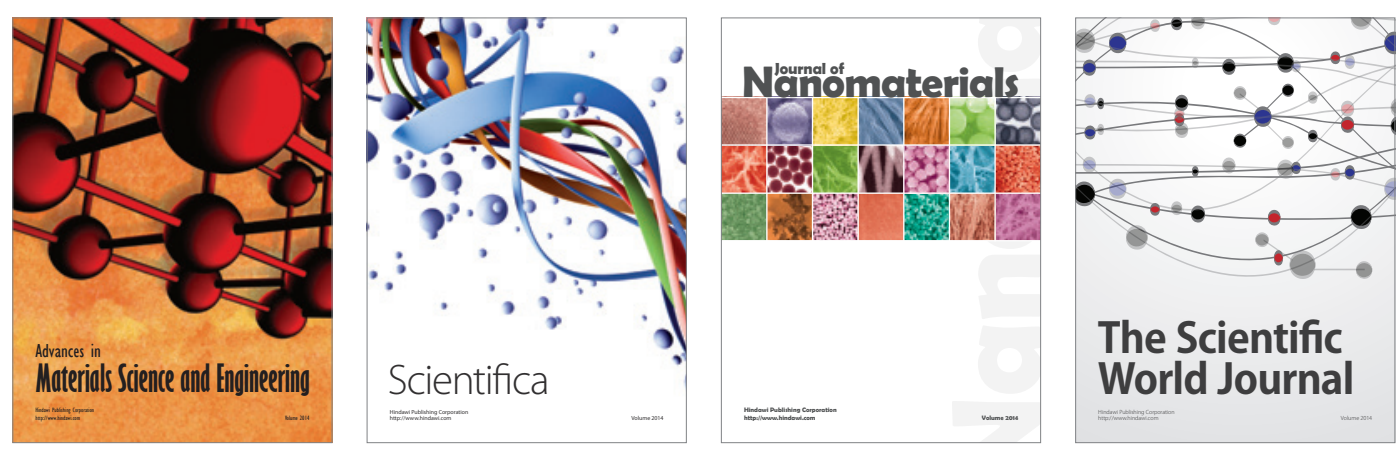

\section{The Scientific World Journal}
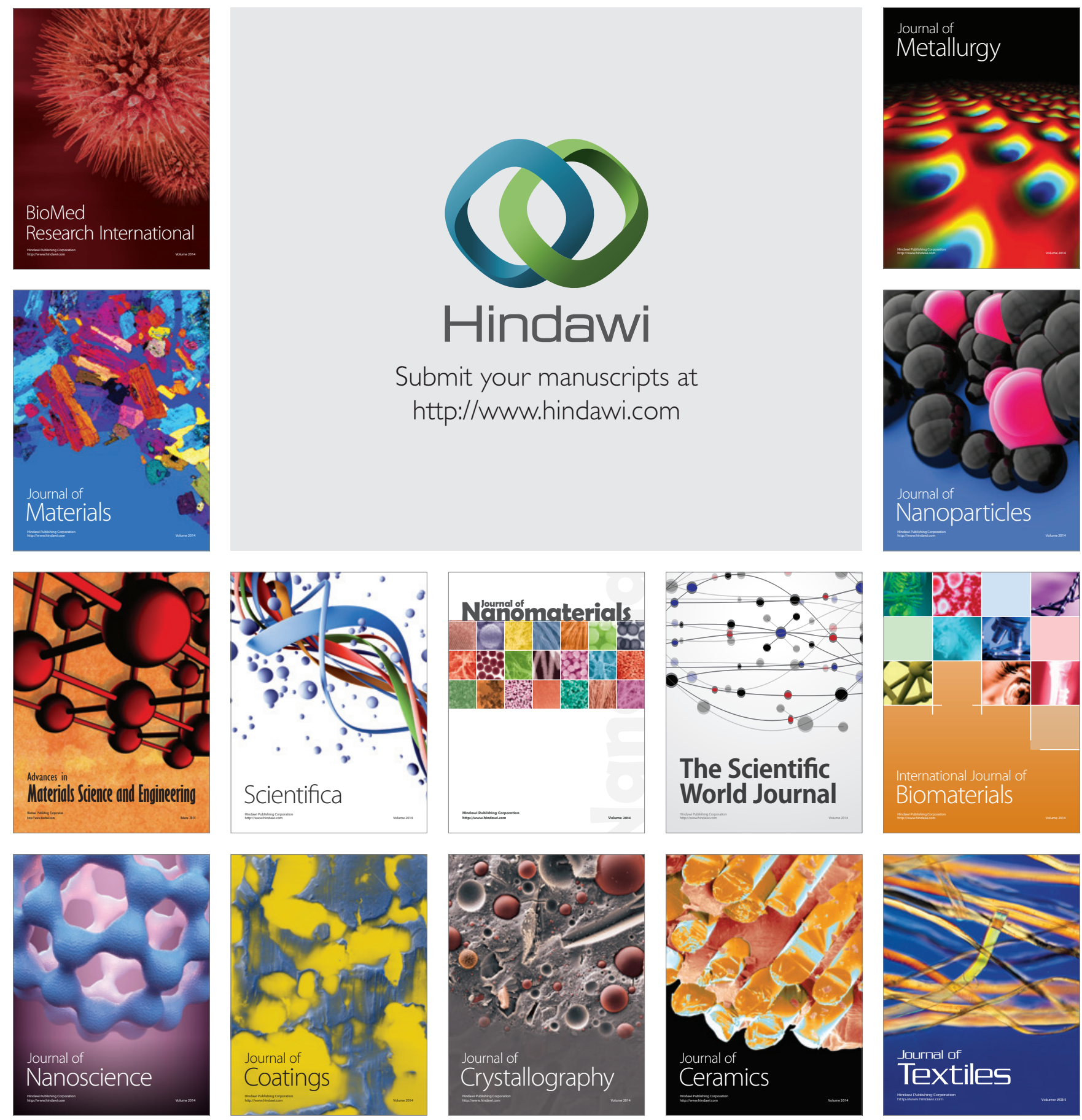